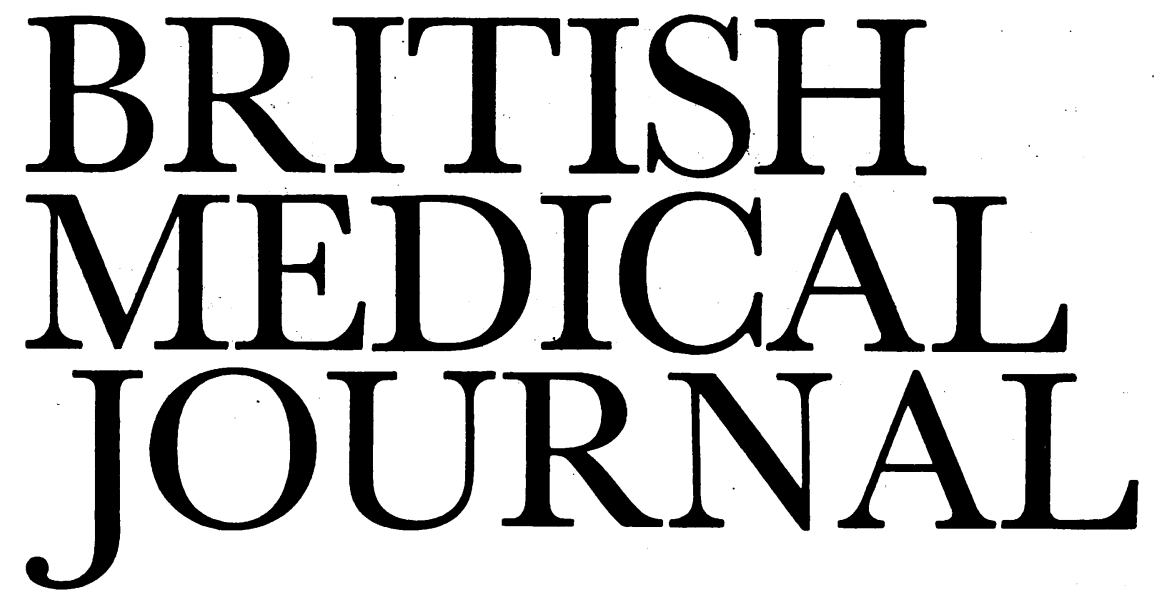

LONDON, SATURDAY 7 MARCH 1987

\title{
New evidence on childhood leukaemia and nuclear establishments
}

Towards the end of 1983 my colleagues and I accepted the poisoned chalice of looking into claims made by Yorkshire Television of "an increased incidence of cancer in the vicinity of the Sellafield site." We were also asked "to act as speedily as was consistent with the rigorous investigation of the situation." By Sizewell standards we certainly achieved speed, publishing a report in mid-1984'; and we had the additional satisfaction (not too common in my experience) that our conclusions and recommendations were accepted without qualification by the government. Some recommendations have already been implemented, notably the establishment of a health oriented monitoring body, the Committee on Medical Aspects of Radiation in the Environment (COMARE), which produced its first report last year. ${ }^{2}$

But what of accuracy? Would we still be prepared to stand by the "qualified reassurance" that we gave to those living around Sellafield? I can give only a personal answer-to do otherwise would mean reconvening the committee without authorisation and usurping the job of COMARE. I defend the views that we expressed at the time and suggest that subsequent events have not greatly altered the place of living near Sellafield in the scale of natural or man made hazards. The actual risk of living there has not changed and should even be diminishing as methods for reprocessing nuclear waste improve; but the perception of risk must have been enhanced, most notably by the Chernobyl disaster, however irrelevant that may be to the practice at Sellafield. (In our report we were careful to make a distinction between the risks of the normal operation of a plant and those of an accident arising from human error. I am, of course, concerned that disclosure of past radiation leaks to our committee seems to have been incomplete ${ }^{2}$; but this economy of truth seems itself to have been economical in that the corrected figures are still well below natural background.) An extensive and independent report from the Office of Population Censuses and Surveys due to be published shortly suggests that there is no general and consistent hazard arising from living near a nuclear installation, even though there are some particular associations that may warrant further detailed study.

The epidemiological evidence that we reviewed showed no overall disadvantage to health from living in west Cumbria; but there was a high likelihood that in small areas near
Sellafield there was an increased risk of leukaemia in young children. Our reassurance thus had to be qualified-even if the number of children affected was small, fewer than 10 over 30 years. We also had to draw attention to the epidemiological fallacy of starting with discovered cases and then deciding on a population and time period rather than the other way round. This point has been even more clearly stated in the survey of childhood leukaemia in Berkshire published on $\mathrm{p}$ 597: "The Sellafield data should be viewed as generating, rather than testing, the hypothesis that the incidence of childhood cancers is increased around nuclear establishments."

Even taking this point, the likelihood of a connection between nuclear plants and childhood leukaemia is enhanced by the finding of an increased incidence of leukaemia near Dounreay (p 603). Much greater amounts of radioactive material are handled at Sellafield and Dounreay than at ordinary nuclear power stations, whose continued operation is dependent on the reprocessing at those two sites of the waste that they generate. The Dounreay paper compares radiation from nuclear installations with radiation from fall out, which may be a better model for the effects of low level radiation than the experience after Hiroshima. But the authors are no more successful than we were ${ }^{1}$ in accounting for the gap between the number of cases of childhood leukaemia expected from estimating radiation exposure and the larger number seen. The continuing lack of an alternative explanation does not, however, prove that either the estimates of radiation exposure or the prevailing assumptions on the biological effects of radiation are seriously wrong. Disquieting in another way is the finding of increased childhood leukaemia around the defence establishments at Aldermaston and Burghfield, where presumably the amount of radioactive material, though unknown, must be much less than that at Sellafield or Dounreay.

There are thus suggestions of a small but definite increase in childhood leukaemia around places where substantial amounts of radioactive material are being handled. Does this mean we should abandon nuclear power? That is clearly not a medical question but a divisive political and economic one; but as citizens we have to try to answer it, without pretending to be experts. Our civilisation needs, or at any rate uses, ever increasing amounts of energy. My own bias is strongly 
against those who demand all the amenities that flow from applied science and yet denigrate their source. For now nuclear fission seems the only long term source of energy on the required scale; but should we not be pressing ahead more actively with the peaceful development of nuclear fusion, which does not release radioactivity into the environment?

Douglas BLACK

Chairman of the Independent Advisory Group

on Cancer in West Cumbria,

Whitchurch-on-Thames RG8 7EN

1 Independent Advisory Group. Investigation of the possible increased incidence of cancer in west Cumbria. London: HMSO, 1984.

2 Committee on Medical Aspects of Radiation in the Environment (COMARE). First report. London: HMSO, 1986.

\section{Chlormethiazole and alcohol: a lethal cocktail}

"Prescription for death" and "Deadly potion" ran the banner headlines in a recent edition of a south coast newspaper. ${ }^{12}$ The articles claimed that local general practitioners were unwittingly feeding a black market in chlormethiazole (Heminevrin) among alcoholics and that the practice had resulted in several deaths. This is not the first time that the risks of chlormethiazole abuse have gained prominence in the media. $^{3}$

The hypnotic, anxiolytic, and anticonvulsant properties of chlormethiazole ${ }^{4}$ make it an attractive choice for treating the excitatory state that characterises withdrawal from alcohol. ${ }^{5}$ In a rapidly reducing dosage regimen over six days chlormethiazole is highly effective ${ }^{6}$ and is now the most popular drug for alcohol withdrawal in Britain. ${ }^{7}$ If the drug is used long term, however, alcoholics readily transfer dependency to it $^{68-10}$ and may visit several general practitioners ${ }^{8}$ or hospitals ${ }^{11}$ in a short time to obtain supplies. Often alcohol abuse continues, ${ }^{12}{ }^{13}$ provoking an adaptation of the central nervous system that increases the dose of chlormethiazole needed to produce the desired effect. ${ }^{12}{ }^{14}$ Such cross tolerance may explain why some alcoholics take more than $25 \mathrm{~g}$ daily. ${ }^{8}$

Especially if drinking continues, the outcome of chlormethiazole abuse is often serious self poisoning with deep coma and centrally mediated respiratory depression that may kill. ${ }^{12}$ Alcohol increases the bioavailability of chlormethiazole, ${ }^{15} 16$ probably by impairing its normally extensive first pass hepatic metabolism..$^{17-20}$ In patients with alcoholic cirrhosis systemic bioavailability may be increased tenfold ${ }^{20}$ mainly because of extrahepatic and intrahepatic venous shunting. ${ }^{21}$ Nevertheless, direct additive pharmacological effects and enhanced cerebral sensitivity to chlormethiazole are probably much more important than kinetic interactions. ${ }^{21}$

All sedatives and hypnotics effective in treating alcohol withdrawal, including the benzodiazepines, share the dangers of tolerance, dependency, and potentially lethal interactions with alcohol..$^{51722}$ The particular association of chlormethiazole with these problems may reflect its popularity. A recent survey suggested that half the alcoholics requiring detoxification in Britain are managed at home by general practitioners who favour chlormethiazole and are prepared to continue its prescription long term. ${ }^{23}$ Such an approach is in sharp conflict with the warnings of the hazards of prolonged chlormethiazole treatment for ambulant alcoholics in published reports ${ }^{891213}$ and from the manufacturers. ${ }^{24}$

General practitioners who start outpatient detoxification must be prepared to provide close supervision. Issuing prescriptions for only one day's supply at a time should ensure daily contact and minimise but not abolish the potential for abuse. ${ }^{12} 22$ If the patient shows any evidence of tolerance to or dependency on chlormethiazole or of continuing to drink alcohol the only safe policy is rapid admission for inpatient care.

GORDON T MCINNES

Senior Lecturer,

University Department of Medicine,

Gardiner Institute,

Western Infirmary,

Glasgow G11 6NT

1 Bailey J. Prescription for death. Southern Evening Echo 1986 Nov 12:1

2 Bailey J. Deadly potion. Southern Evening Echo 1986 Nov 12:3.

3 Anonymous. Doctor warns of madness drug. Daily Record 1979 May 3:31 (col 1)

4 Evans JG, Feuerlein W, Glatt MM, Kanowski S, Scott DB, eds. Chlormethiazole 25 years: recent developments and historical perspectives. Acta Psychiatr Scand 1986;73 (suppl 329):1-198.

5 Rosenbloom AJ. Optimising drug treatment of alcohol withdrawal. Am f Med 1986;81:901-4.

6 Glatt MM, George HR, Frisch EP. Controlled trial of chlormethiazole in treatment of the alcoholic withdrawal phase. BrMed f 1965;ii:401-4.

Anonymous. Management of alcohol withdrawal symptoms. [Editorial.] BrMed $\mathcal{f} 1981 ; 282: 502$.

8 Foster A. Sedatives for alcoholics. Br Med J 1977;i: 1355.

9 Hession MA, Verma S, Bhakta KGM. Dependence on chlormethiazole and effects of its withdrawal. Lancet 1979; i:953-4.

10 Lundquist G. The clinical use of chlormethiazole. Acta Psychiatr Scand 1966;42 (suppl 192):113-4.

11 Cushnie JM, Ben-Tovim DI, Kopelman P. Chlormethiazole addiction: unusual presentation BrMed f 1978;ii:355.

12 Horder JM. Fatal chlormethiazole poisoning in chronic alcoholics. Br Med f 1978;i:693-4.

13 Illingworth RN, Stewart MJ, Jarvie DR. Severe poisoning with chlormethiazole. Br Med $\mathcal{J}$ 1979;ii:902-3.

14 Kalant H, Khanna JM, Llewellyn M, Rinkel GJE, Woodworth I. Functional tolerance to chlormethiazole and cross-tolerance to ethanol in the rat: importance of test and mode of drug administration. Acta Psychiatr Scand 1986;73 (suppl 329):54-65.

15 Neuvonen PJ, Pentikäinen PJ, Jostell KG, Syvälahti E. The pharmacokinetics of chlormethiazole in healthy subjects as affected by ethanol. Clin Pharmacol Ther 1981;29:268-9.

16 Zysset T, Bircher J. Preferential reduction of first-pass elimination by ethanol. Model experiment with chlormethiazole in the rabbit. F Pharmacol Exp Ther 1981;217:198-203.

17 Linnoila M, Mattila MJ, Kitchell BS. Drug interactions with alcohol. Drugs 1979;18:299-311.

18 Moore RG, Triggs EJ, Shanks CA, Thomas J. Pharmacokinetics of chlormethiazole in humans. Eur f Clin Pharmacol 1975;8:353-7.

19 Nation RL, Vine J, Triggs EJ, Learoyd B. Plasma levels of chlormethiazole and two metabolites after oral administration to young and aged human subjects. Eur 7 Clin Pharmacol 1977;12:137-45.

20 Pentikäinen PJ, Neuvonen PJ, Tarpila S, Syvälahti E. Effect of cirrhosis of the liver on the pharmacokinetics of chlormethiazole. BrMed J 1978;ii:861-3.

21 Hoyumpa AM, Schenker S. Major drug interactions: effect of liver disease, alcohol and malnutrition. Annu Rev Med 1982;33:113-49.

22 Solomon F, White CC, Parron DL, Mendelson WB. Special report-sleeping pills, insomnia and medical practice. N Engl f Med 1979;300:803-8.

23 Stockwell T, Bolt E, Hooper J: Detoxification from alcohol at home managed by general practitioners. Br Med J 1986;292:733-5.

24 Association of the British Pharmaceutical Industry. Data sheet compendium 1986-87. London: ABPI, 1986:102-4.

\section{Stopping bleeding by embolisation}

Bleeding can usually be managed conservatively, but sometimes an operation may be necessary. Often those patients who do need an operation are old or ill; sometimes they have already had one operation. These sorts of patients may be candidates for transcatheter embolisation of their bleeding point, particularly as angiography will often be necessary to localise that point. ${ }^{1}$

Few parts of the body are inaccessible to modern catheter techniques, which are all performed under local anaesthesia. Once a bleeding site has been located (and it is usually surprisingly small) a catheter is manipulated as near as possible to it so that embolisation can be carried out. Many different materials are used as the embolus and many occlusion techniques are available, ${ }^{1}$ but the materials most 